\title{
Increased induction in FeCo-based nanocomposite materials with reduced early transition metal growth inhibitors
}

\author{
K. J. Miller, ${ }^{1, a)}$ A. Leary, ${ }^{1}$ S. J. Kernion, ${ }^{1}$ A. Wise, ${ }^{1}$ D. E. Laughlin, ${ }^{1}$ M. E. McHenry, ${ }^{1}$ \\ Vladimir Keylin, ${ }^{2}$ and Joe Huth ${ }^{2}$ \\ ${ }^{1}$ Department of Materials Science and Engineering, Carnegie Mellon University, Pittsburgh, Pennsylvania \\ 15213, USA \\ ${ }^{2}$ Magnetics Technology Center, Division of Spang \& Company, Pittsburgh, Pennsylvania 15238, USA
}

(Presented 21 January 2010; received 20 October 2009; accepted 7 December 2009; published online 19 April 2010)

\begin{abstract}
We report on new high-saturation induction, high-temperature nanocomposite alloys with reduced glass formers. The amounts of the magnetic transition metals and early transition metal growth inhibitors were systematically varied to determine trade-offs between higher inductions and fine microstructures with consequently lower magnetic losses. Alloys of nominal composition $\left(\mathrm{Fe}_{65} \mathrm{Co}_{35}\right)_{79.5+\mathrm{x}} \mathrm{Nb}_{4-\mathrm{x}} \mathrm{B}_{13} \mathrm{Si}_{2} \mathrm{Cu}_{1.5}(\mathrm{x}=0-4)$ were cast into a $28 \mathrm{~mm}$ wide, $20 \mu \mathrm{m}$ thick ribbon from which toroidal cores were wound. Inductions and magnetic losses were measured after nanocrystallization and stress relief. We report technical magnetic properties: permeability, maximum induction, remanence ratio, coercive field, and high frequency magnetic losses as a function of composition and annealing temperature for these alloys. Of note is the development of maximum inductions in excess of $1.76 \mathrm{~T}$ in cores made of alloys with the $\mathrm{x}=4$ composition and maximum inductions in excess of $1.67 \mathrm{~T}$ in alloys with the $\mathrm{x}=3$ composition, which also exhibit power losses smaller than $10 \mathrm{~W} / \mathrm{kg}$ at $0.2 \mathrm{~T}$ induction levels in $20 \mathrm{kHz}$ fields. We discuss optimization of induction with chemistry and correlate the microstructures with losses. (C) 2010 American Institute of Physics. [doi:10.1063/1.3350900]
\end{abstract}

\section{INTRODUCTION}

The need for magnetic materials in vehicle electrical power systems is motivated by a desire to replace transformers and other power electronic components with those that can operate at higher power densities, at higher frequencies and temperatures in extreme environments. ${ }^{1}$ This requires soft magnetic materials that operate at high temperatures with high inductions and low losses. Systems can be made smaller and lighter by size and weight reductions of the magnetic passive components. The combination of materials properties required puts significant constraints on the choices of materials, and often trade-offs between these desirable properties must be made for a given application.

Nanocomposites have ultrafine nanocrystalline grains, often nucleating on $\mathrm{Cu}$ clusters, homogeneously dispersed in an amorphous matrix that is enriched in metalloid glass formers and early transition metal growth inhibitors. ${ }^{2}$ Nanocrystalline soft magnetic alloys based on the FeCo system called HITPERM have been reported for high-temperature application. ${ }^{3,4}$ Work on these alloys has concentrated on materials with Fe:Co ratios of 50:50 (Ref. 3) where low magnetocrystalline anisotropy is observed in bulk alloys; 65:3570:30 (Ref. 5) near the peak in the Slater-Pauling curve; and less than 10:90 (Refs. 6 and 7), which sacrifice induction for improved mechanical properties, stronger response to magnetic field processing, and potentially lower losses from magnetostriction. This work is aimed at investigating further development of materials with the largest inductions.

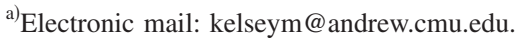

A new class of FeCo-based experimental nanocomposite alloys that exhibit high-saturation induction, hightemperature stability, and low loss has recently been developed and characterized. ${ }^{8,9}$ From this family of materials, an alloy commercialized under the designation HTX-002 was selected for use in an inductor for a future hybrid ground vehicle $25 \mathrm{~kW}$ dc-dc prototype converter. ${ }^{1}$ This paper presents the compositional modifications of this nanocomposite alloy, aimed at further increasing the induction by reducing amounts of the nonmagnetic growth inhibitors in the alloy. Since the soft magnetic properties of these alloys are rooted in the averaging of random magnetic anisotropies over all nanocrystalline grains in an exchange volume,${ }^{10}$ the growth inhibitors are necessary to ensure a fine microstructure with low magnetic losses.

The extent to which the growth inhibitors can be limited to achieve larger inductions without undo increases in the magnetic losses is the subject of this work. We quantify the role of reduced growth inhibitor concentrations on the magnetic inductions of alloys with compositions $\left(\mathrm{Fe}_{65} \mathrm{Co}_{35}\right)_{79.5+\mathrm{x}} \mathrm{Nb}_{4-\mathrm{x}} \mathrm{B}_{13} \mathrm{Si}_{2} \mathrm{Cu}_{1.5}(\mathrm{x}=0-4)$. We correlate the reduction in growth inhibitor concentrations with the increase in magnetic induction and magnetic losses in these alloys. Finally, we correlate the magnetic losses with the microstructures, which observed in these materials.

The development of higher magnetic inductions in alloys of this genre leads to improvements in applications as diverse as reducing the size and/or mass of power transformation components (power transformers, pulse transformers, 
and various inductors) and for improved ferromagnetic resonance frequency in electromagnetic interference absorber materials.

\section{MATERIAL DEVELOPMENT}

New HTX-002 alloys designed to achieve a higher saturation magnetizations were screened at Carnegie Mellon University (CMU). First, the Fe:Co ratio was optimized. The prior HTX-002 alloys developed by Magnetics had a 70:30 atomic ratio of $\mathrm{Fe}$ :Co. Four new alloys were cast at CMU, which varied this Fe:Co atomic ratio from 60:40 to 75:25 in 5 at. \% steps. Amorphous ribbons were synthesized by arcmelting and melt-spinning on a water-cooled UNS C17510 beryllium copper wheel (thermal conductivity of $k$ $=240 \mathrm{~W} / \mathrm{m} \mathrm{K}$ ). Alloys were cast using the same glass formers to be cast in air ( $\mathrm{Nb}, \mathrm{Si}$, and $\mathrm{B})$ so as to have a direct comparison with the alloys that are transferred to Magnetics for casting on the planar flow caster (PFC). We determined the $\mathrm{Fe}: \mathrm{Co}$ atomic ratio of 65:35 to yield the highest saturation magnetization in agreement with the binary alloy SlaterPauling curve. Using ingots supplied by Magnetics containing 0 and 4 at. $\% \mathrm{Nb}$, alloys in 1 at. $\% \mathrm{Nb}$ increments were cast at CMU.

Maintaining the $\mathrm{Fe}: \mathrm{Co}$ at the 65:35 optimum saturation magnetization, nanocomposite soft magnetic alloys of compositions $\left(\mathrm{Fe}_{65} \mathrm{Co}_{35}\right)_{79.5+\mathrm{x}} \mathrm{Nb}_{4-\mathrm{x}} \mathrm{B}_{13} \mathrm{Si}_{2} \mathrm{Cu}_{1.5} \quad(\mathrm{x}=0-4)$ were cast into ingots and analyzed by inductively coupled plasma spectrometry to confirm that the target chemistries were achieved. Niobium was chosen as the growth inhibitor of nanocrystals because of its lower oxidation potential for casting in air. Ingots were processed using PFC equipment for remelting and ribbon production.

Phase identification and microstructural investigations of the cast ribbon in its nanocrystalline state were determined using x-ray diffraction (XRD), scanning transmission electron microscopy (STEM), and energy dispersive $\mathrm{x}$-ray analysis (EDX) scans, while differential thermal analysis (DTA) was used to determine crystallization peaks. DTA was done using analyzer NETZSCH STA 409 model, with $5{ }^{\circ} \mathrm{C} / \mathrm{min}$ heating rate.

Toroidal wound cores were annealed in flowing $\mathrm{N}_{2}$ at varying temperatures for $1 \mathrm{~h}$ with a $2.0 \mathrm{~T}$ transverse magnetic field (TMF). The hysteresis loop parameters (maximum flux density, remnant induction, and coercive field) were measured at $400 \mathrm{~Hz}$ and $\mathrm{H}_{\mathrm{m}}=8 \mathrm{kA} / \mathrm{m}$ on a Walker Scientific Hysteresisgraph AMH-25. Watt loss at selected frequencies and inductions was tested with Power Analyzer Norma D-6000.

\section{RESULTS AND DISCUSSION}

The DTA curves all show three crystallization peaks. Depending on composition, the onset of primary crystallization began at 361 and $414{ }^{\circ} \mathrm{C}$ for $0 \% \mathrm{Nb}$ and $4 \% \mathrm{Nb}$, with a maximum at 390 and $436{ }^{\circ} \mathrm{C}$, respectively (see Fig. 1). The XRD pattern of the cast ribbon in its nanocrystalline state after TMF annealing amorphous precursors in an $\mathrm{N}_{2}$ atmo-

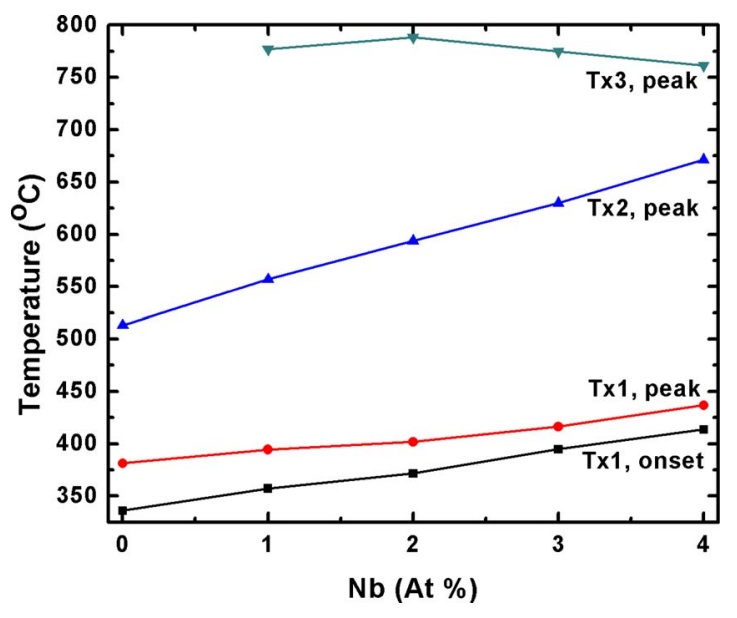

FIG. 1. (Color online) DTA curves at various Nb concentrations showing onset of primary crystallization.

sphere at varying temperatures for $1 \mathrm{~h}$ showed broad diffraction peaks, indicating that the primary crystallization product had a bcc FeCo-based structure.

After transverse field annealing, the cores are expected to have a flat hysteresis loop with low remnant induction (squareness ratio), coercive field, and watt loss. The low squareness gives high $\Delta \mathrm{B}$, which is important for pulse transformers with unipolar pulse shape and other inductor applications. Of note is the development of maximum inductions in excess of $1.76 \mathrm{~T}$ in cores made of alloys with the $\mathrm{x}=4$ composition. However, the alloys with lower $\mathrm{Nb}$ content also exhibit higher coercivity and remanence ratio. The permeability and maximum flux density versus temperature plots for alloys with $\mathrm{x}=0-4$ compositions are shown in Fig. 2.

Figure 3 shows power loss versus annealing temperature for alloys with reduced growth inhibitor concentration (maximum induction $=0.2 \mathrm{~T}$ and $\mathrm{f}=20 \mathrm{kHz}$ ). Losses were measured to be 3.7 and $6.2 \mathrm{~W} / \mathrm{kg}$ for the 4 and 2 at. $\% \mathrm{Nb}$ concentrations, respectively. Maximum inductions in excess of $1.67 \mathrm{~T}$ in alloys with the $\mathrm{x}=3$ composition also exhibit power losses smaller than $10 \mathrm{~W} / \mathrm{kg}$ using the field parameters above.
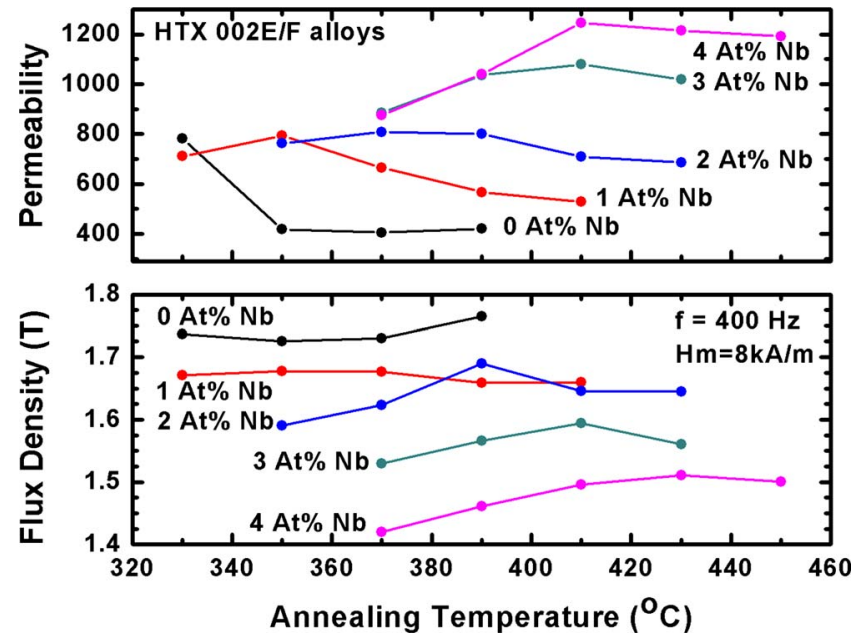

FIG. 2. (Color online) Permeability and induction for alloys with $0 \%-4 \%$ $\mathrm{Nb}$ growth inhibitor. 


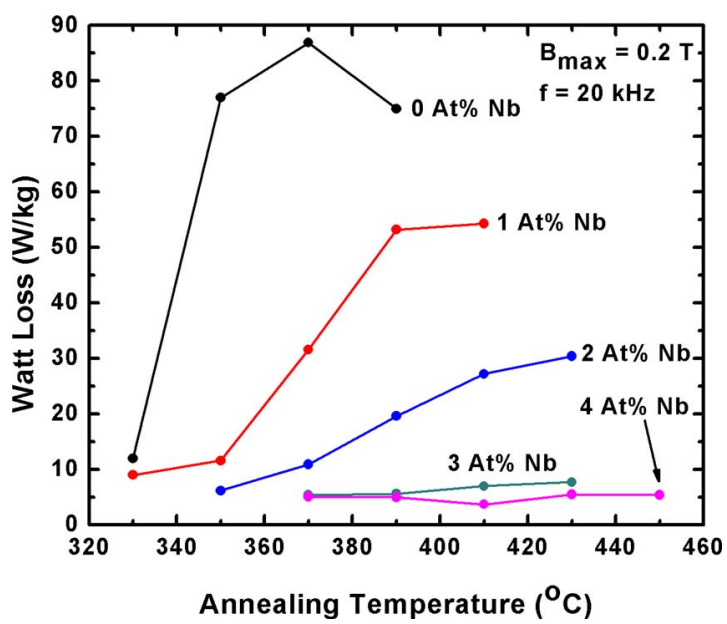

FIG. 3. (Color online) Power loss at a maximum induction of $0.2 \mathrm{~T}$ and a frequency of $20 \mathrm{kHz}$ for alloys with reduced growth inhibitor concentration.

STEM micrographs show the difference in density between the crystallites and the amorphous matrix; with crystallites appearing lighter in color than the amorphous material (see Fig. 4). As can be seen from the micrographs, the crystallites in the 1 at. \% $\mathrm{Nb}$ sample are significantly larger and more regular in appearance than the crystallites present in the 4 at. $\% \mathrm{Nb}$ sample. The 1 at. $\% \mathrm{Nb}$ particles average $29 \mathrm{~nm} \pm 8.7 \mathrm{~nm}$, and the 4 at. $\% \mathrm{Nb}$ particles average $13.3 \mathrm{~nm} \pm 6.1 \mathrm{~nm}$. The large deviations are due to the many smaller particles embedded with the larger more visible particles. The mix of very small grains with the larger grains formed leads to the large standard deviations.

\section{CONCLUSION}

A new high-saturation induction nanocrystalline alloy of composition $\left(\mathrm{Fe}_{65} \mathrm{Co}_{35}\right)_{79.5+\mathrm{x}} \mathrm{Nb}_{4-\mathrm{x}} \mathrm{B}_{13} \mathrm{Si}_{2} \mathrm{Cu}_{1.5}(\mathrm{x}=0-4)$ with lower glass former concentration for high power inductors has been developed. Maximum inductions in excess of 1.67 $\mathrm{T}$ in alloys with the $\mathrm{x}=3$ composition also exhibit power losses smaller than $10 \mathrm{~W} / \mathrm{kg}$ at $0.2 \mathrm{~T}$ induction levels in 20

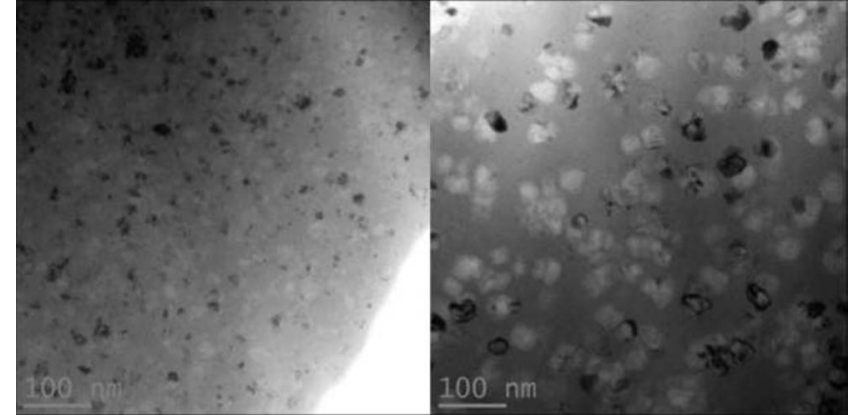

FIG. 4. STEM micrographs of $\mathrm{x}=4$ (left) and $\mathrm{x}=1$ (right) compositions showing differences in crystallite size.

$\mathrm{kHz}$ exciting fields. Microstructural investigations of these alloys reveal significant grain size difference between 1 and 4 at. $\% \mathrm{Nb}$, attributing to the higher power losses in the 1 at. $\% \mathrm{Nb}$ sample.

\section{ACKNOWLEDGMENTS}

K.J.M. and M.E.M. acknowledge support from the ARL through Grant No. W911NF-08-2-0024.

${ }^{1}$ J. Long, M. E. McHenry, D. Urciuoli, V. Keylin, J. Huth, and T. Salem, J. Appl. Phys. 103, 07E705 (2008).

${ }^{2}$ M. E. McHenry, M. A. Willard, and D. E. Laughlin, Prog. Mater. Sci. 44, 291 (1999).

${ }^{3}$ M. A. Willard, D. E. Laughlin, M. E. McHenry, D. Thoma, K. Sickafus, J.

O. Cross, and V. G. Harris, J. Appl. Phys. 84, 6773 (1998).

${ }^{4}$ D. H. Ping, Y. Q. Wu, K. Hono, M. A. Willard, M. E. McHenry, and D. E. Laughlin, Scr. Mater. 45, 781 (2001).

${ }^{5}$ H. Iwanabe, B. Lu, M. E. McHenry, and D. E. Laughlin, J. Appl. Phys. 85, 4424 (1999)

${ }^{6}$ P. R. Ohodnicki, S. Y. Park, D. E. Laughlin, M. E. McHenry, V. Keylin, and M. A. Willard, J. Appl. Phys. 103, 07E729 (2008).

${ }^{7}$ P. R. Ohodnicki, H. McWilliams, D. E. Laughlin, M. E. McHenry, and V. Keylin, J. Appl. Phys. 103, 07E740 (2008).

${ }^{8}$ J. Long, P. R. Ohodnicki, D. E. Laughlin, M. E. McHenry, T. Ohkubo, and K. Hono, J. Appl. Phys. 101, 09N114 (2007).

${ }^{9}$ J. Long, Y. Qin, N. T. Nuhfer, M. De Graef, D. E. Laughlin, and M. E. McHenry, J. Appl. Phys. 101, 09N115 (2007).

${ }^{10}$ G. Herzer, IEEE Trans. Magn. 26, 1397 (1990). 